\title{
Hysteroscopy and COVID-19: Have recommended techniques changed due to the pandemic?
}

\author{
Be cognizant to follow these recommendations for minimizing the risk \\ of viral spread during hysteroscopic procedures
}

Laura Florez, MD, and Jose Carugno, MD

IN THIS ARTICLE

Viral dissemination risk

page 37

\section{Recommendations} for the office

page 40

Recommendations for the OR page 40
(20) he emergence of the coronavirus severe acute respiratory syndrome coronavirus 2 (SARS-CoV-2) infection (COVID-19) in December 2019, has resulted in a global pandemic that has challenged the medical community and will continue to represent a public health emergency for the next several months. ${ }^{1}$ It has rapidly spread globally, infecting many individuals in an unprecedented rate of infection and worldwide reach. On March 11, 2020, the World Health Organization designated COVID-19 as a pandemic. While the majority of infected individuals are asymptomatic or develop only mild symptoms, some have an unfortunate clinical course resulting in multi-organ failure and death. ${ }^{2}$

It is accepted that the virus mainly spreads during close contact and via respiratory drop-

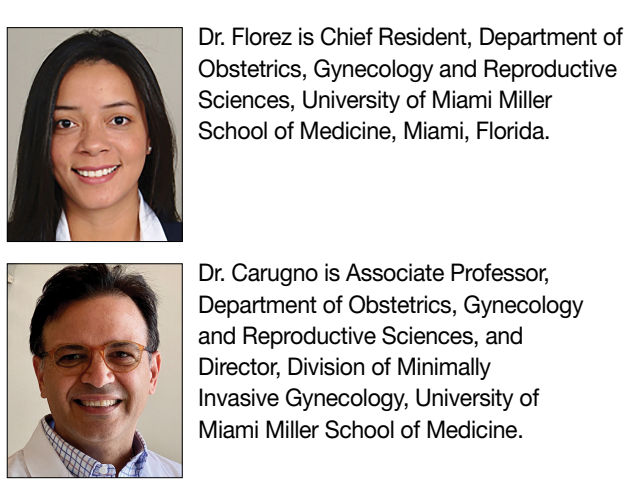

The authors report no financial relationships relevant to this article.

doi: 10.12788/obgm.0027 lets. $^{3}$ The average time from infection to onset of symptoms ranges from 2 to 14 days, with an average of 5 days. ${ }^{4}$ Recommended measures to prevent the spread of the infection include social distancing (at least 6 feet from others), meticulous hand hygiene, and wearing a mask covering the mouth and nose when in public. ${ }^{5}$ Aiming to mitigate the risk of viral dissemination for patients and health care providers, and to preserve hospital resources, all nonessential medical interventions were initially suspended. Recently, the American College of Surgeons in a joint statement with 9 women's health care societies have provided recommendations on how to resume clinical activities as we recover from the pandemic. ${ }^{6}$

As we reinitiate clinical activities, gynecologists have been alerted of the potential risk of viral dissemination during gynecologic minimally invasive surgical procedures due to the presence of the virus in blood, stool, and the potential risk of aerosolization of the virus, especially when using smoke-generating devices. ${ }^{7,8}$ This risk is not limited to intubation and extubation of the airway during anesthesia; the risk also presents itself during other aerosol-generating procedures, such as laparoscopy or robotic surgery. . $^{9,10}$

Hysteroscopy is considered the gold standard procedure for the diagnosis and management of intrauterine pathologies. ${ }^{11} \mathrm{It}$ is frequently performed in an office setting without the use of anesthesia. ${ }^{11,12}$ It is usually well tolerated, with only a few patients 


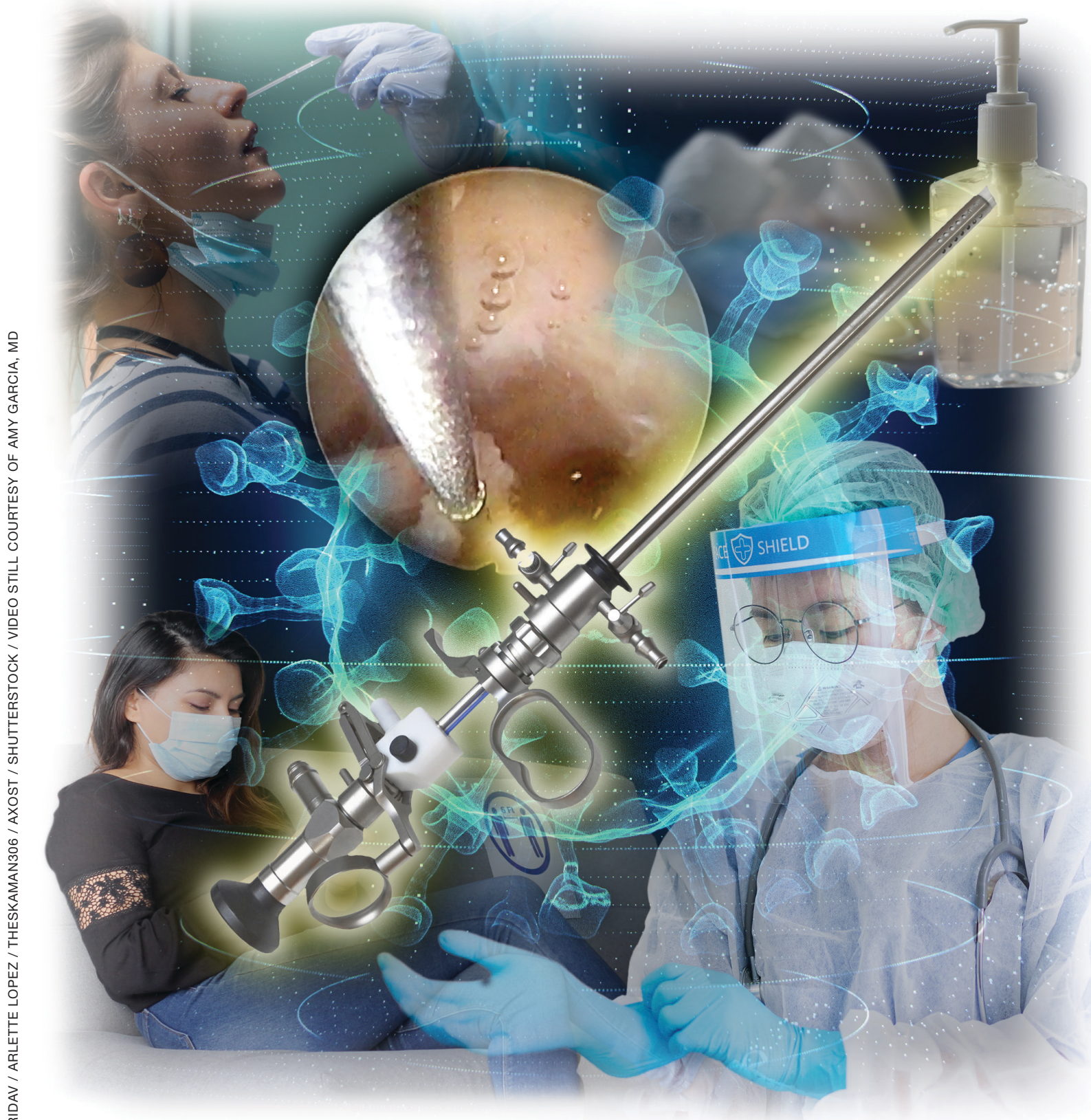

reporting discomfort. ${ }^{12}$ It allows for immediate treatment (using the "see and treat" approach) while avoiding not only the risk of anesthesia, as stated, but also the need for intubationwhich has a high risk of droplet contamination in COVID-19-infected individuals. ${ }^{13}$

\section{Is there risk of viral dissemination during hysteroscopic procedures?}

The novel and rapidly changing nature of the COVID-19 pandemic present many challenges to the gynecologist. Significant concerns have been raised regarding potential risk of viral dissemination during laparoscopic surgery due to aerosolization of viral particles and the presence of the virus in blood and the gastrointestinal tract of infected patients. ${ }^{7}$ Diagnostic, and some simple, hysteroscopic procedures are commonly performed in an outpatient setting, with the patient awake. Complex hysteroscopic interventions, however, are generally performed in the operating room, typically with the use of general anesthesia. Hysteroscopy has the theoretical risks of viral dissemination when performed in COVID-19-positive patients. Two important questions must be addressed to better understand the potential risk of COVID-19 viral dissemination during hysteroscopic procedures. 


\section{Hysteroscopy and COVID-19}

CONTINUED FROM PAGE 37

$\overline{\text { FAST }}$

TRACK

Although
the smoke
generated during
hysteroscopy
is not released
into the air,
necessary
precautions
should be
undertaken
to minimize
COVID-19

transmission risk

\section{Is the virus present in the vaginal fluid of women infected with COVID-19?}

Recent studies have confirmed the presence of viral particles in urine, feces, blood, and tears in addition to the respiratory tract in patients infected with COVID-19., ${ }^{3,14,15}$ The presence of the SARS-CoV-2 virus in the female genital system is currently unknown. Previous studies, of other epidemic viral infections, have demonstrated the presence of the virus in the female genital tract in affected patients of Zika virus and Ebola. ${ }^{16,17}$ However, 2 recent studies have failed to demonstrate the presence of the SARS-CoV-2 virus in the vaginal fluid of pregnant ${ }^{14}$ and not pregnan $t^{18}$ women with severe COVID-19 infection.

\section{Is there risk of viral dissemination during hysteroscopy if using electrosurgery?}

There are significant concerns with possible risk of COVID-19 transmission to health care providers in direct contact with infected patients during minimally invasive gynecologic procedures due to direct contamination and aerosolization of the virus. ${ }^{10,19}$ Current data on COVID-19 transmission during surgery are limited. However, it is important to recognize that viral aerosolization has been documented with other viral diseases, such as human papillomavirus and hepatitis $\mathrm{B} \cdot{ }^{20} \mathrm{~A}$ recent report called for awareness in the surgical community about the potential risks of COVID-19 viral dissemination during laparoscopic surgery. Among other recommendations, international experts advised minimizing the use of electrosurgery to reduce the creation of surgical plume, decreasing the pneumoperitoneum pressure to minimum levels, and using suction devices in a closed system. ${ }^{21}$ Although these preventive measures apply to laparoscopic surgery, it is important to consider that hysteroscopy is performed in a unique environment.

During hysteroscopy the uterine cavity is distended with a liquid medium (normal saline or electrolyte-free solutions); this is opposed to gynecologiclaparoscopy, in which the peritoneal cavity is distended with carbon dioxide..$^{22}$ The smoke produced with the use of hysteroscopic electrosurgical instruments generates bubbles that are immediately cooled down to the temperature of the distention media and subsequently dissolve into it. Therefore, there are no bubbles generated during hysteroscopic surgery that are subsequently released into the air. This results in a low risk for viral dissemination during hysteroscopic procedures. Nevertheless, the necessary precautions to minimize the risk of COVID-19 transmission during hysteroscopic intervention are extremely important.

\section{Recommendations for hysteroscopic procedures during the COVID-19 pandemic}

We provide our overall recommendations for hysteroscopy, as well as those specific to the office and hospital setting.

\section{Recommendations: General}

Limit hysteroscopic procedures to COVID-19negative patients and to those patients in whom delaying the procedure could result in adverse clinical outcomes. ${ }^{23}$

Universally screen for potential COVID-19 infection. When possible, a phone interview to triage patients based on their symptoms and infection exposure status should take place before the patient arrives to the health care center. Patients with suspected or confirmed COVID-19 infection who require immediate evaluation should be directed to COVID-19-designated emergency areas.

Universally test for SARS-CoV-2 before procedures performed in the operating room (OR). Using nasopharyngeal swabs for the detection of viral RNA, employing molecular methods such as polymerase chain reaction (PCR), within 48 to 72 hours prior to all OR hysteroscopic procedures is strongly recommended. Adopting this testing strategy will aid to identify asymptomatic SARS-CoV-2-infected patients, allowing to defer the procedure, if possible, among patients testing positive. If tests are limited, testing only patients scheduled for hysteroscopic procedures in which general or regional anesthesia will be required is acceptable.

Universal SARS-CoV-2 testing of patients undergoing in-office hysteroscopic diagnostic 


\section{Hysteroscopy and COVID-19}

CONTINUED FROM PAGE 38

FAST

TRACK

For office
procedures,
minimize

accompanying

companions

to one person

under the age

of 60; For OR

procedures,

limit the number

of personnel in the

procedure room or minor operative procedures without the use of anesthesia is not required.

Limit the presence of a companion. It is understood that visitor policies may vary at the discretion of each institution's guidelines. Children and individuals over the age of 60 years should not be granted access to the center. Companions will be subjected to the same screening criteria as patients.

Provide for social distancing and other precautionary measures. If more than one patient is scheduled to be at the facility at the same time, ensure that the facility provides adequate space to allow the appropriate social distancing recommendations between patients. Hand sanitizers and facemasks should be available for patients and companions.

Provide PPE for clinicians. All health care providers in close contact with the patient must wear personal protective equipment (PPE), which includes an apron and gown, a surgical mask, eye protection, and gloves. Health care providers should wear PPE deemed appropriate by their regulatory institutions following their local and national guidelines during clinical patient interactions.

Restrict surgical attendees to vital personnel. The participation of learners by physical presence in the office or operating room should be restricted.

\section{Recommendations: Office setting}

Preprocedural recommendations

- Advise patients to come to the office alone. If the patient requires a companion, a maximum of one adult companion under the age of 60 should be accepted.

- Limit the number of health care team members present in the procedure room.

Intraprocedural recommendations

- Choose the appropriate device(s) that will allow for an effective and fast procedure.

- Use the recommended PPE for all clinicians.

- Limit the movement of staff members in and out of the procedure room.

Postprocedure recommendations

- When more than one case is scheduled to be performed in the same procedure room, allow enough time in between cases to grant a thorough OR decontamination.
- Allow for patients to recover from the procedure in the same room as the procedure took place in order to avoid potential contamination of multiple rooms.

- Expedite patient discharge.

- Follow up after the procedure by phone or telemedicine.

- Use standard endoscope disinfection procedures, as they are effective and should not be modified.

\section{Recommendations: Operating room setting}

Preprocedural recommendations

- Perform adequate patient screening for potential COVID-19 infection. (Screening should be independent of symptoms and not be limited to those with clinical symptoms.)

- Limit the number of health care team members in the operating procedure room.

- To minimize unnecessary staff exposure, have surgeons and staff not needed for intubation remain outside the OR until intubation is completed and leave the OR before extubation.

\section{Intraprocedure recommendations}

- Limit personnel in the OR to a minimum.

- Staff should not enter or leave the room during the procedure.

- When possible, use conscious sedation or regional anesthesia to avoid the risk of viral dissemination at the time of intubation/ extubation.

- Choose the device that will allow an effective and fast procedure.

- Favor non-smoke-generating devices, such as hysteroscopic scissors, graspers, and tissue retrieval systems.

- Connect active suction to the outflow, especially when using smoke-generating instruments, to facilitate the extraction of surgical smoke.

\section{Postprocedure recommendations}

- When more than one case is scheduled to be performed in the same room, allow enough time in between cases to grant a thorough OR decontamination.

- Expedite postprocedure recovery and patient discharge. 


\section{Hysteroscopy and COVID-19}

CONTINUED FROM PAGE 40

- After completion of the procedure, staff should remove scrubs and change into clean clothing.

- Use standard endoscope disinfection procedures, as they are effective and should not be modified.

\section{Conclusions}

The COVID-19 pandemic has caused a global health emergency. Our knowledge of this devastating virus is constantly evolving as we continue to fight this overwhelming disease. Theoretical risk of "viral" dissemination is considered extremely low, or negligible, during hysterosocopy. Hysteroscopic procedures in COVID-19-positive patients with life-threatening conditions or in patients in whom delaying the procedure could worsen outcomes should be performed taking appropriate measures. Patients who test negative for COVID-19 (confirmed by PCR) and require hysteroscopic procedures, should be treated using universal precautions.

\section{References}

1. Al-Shamsi HO, Alhazzani W, Alhuraiji A, et al. A practical approach to the management of cancer patients during the novel coronavirus disease 2019 (COVID-19) pandemic: an international collaborative group. Oncologist. 2020;25: e936-e945.

2. WuZ, McGoogan JM. Characteristics of and important lessons from the coronavirus disease 2019 (COVID-19) outbreak in China: summary of a report of 72314 cases from the Chinese Center for Disease Control and Prevention. JAMA. February 24, 2020. doi:10.1001/jama.2020.2648.

3. Wang $\mathrm{W}, \mathrm{Xu} \mathrm{Y}, \mathrm{Gao} \mathrm{R}$, et al. Detection of SARS-CoV-2 in different types of clinical specimens. JAMA. 2020;323: 1843-1844.

4. Yu F, Yan L, Wang N, et al. Quantitative detection and viral load analysis of SARS-CoV-2 in infected patients. Clin Infect Dis. 2020;71:793-798.

5. Prem K, Liu Y, Russell TW, et al; Centre for the Mathematical Modelling of Infectious Diseases COVID-19 Working Group. The effect of control strategies to reduce social mixing on outcomes of the COVID-19 epidemic in Wuhan, China: a modelling study. Lancet Public Health. 2020;5:e261-e270.

6. American College of Surgeons, American Society of Aesthesiologists, Association of periOperative Registered Nurses, American Hospital Association. Joint Statement: Roadmap for resuming elective surgery after COVID-19 pandemic. April 16, 2020. https://www.aorn.org/guidelines /aorn-support/roadmap-for-resuming-elective-surgeryafter-covid-19. Accessed August 27, 2020.

7. Zhang W, Du RH, Li B, et al. Molecular and serological investigation of 2019-nCoV infected patients: implication of multiple shedding routes. Emerg Microbes Infect. 2020;9: 386-389.

8. Mowbray NG, Ansell J, Horwood J, et al. Safe management of surgical smoke in the age of COVID-19. Br J Surg. May 3, 2020. doi: 10.1002/bjs.11679.

9. Cohen SL, Liu G, Abrao M, et al. Perspectives on surgery in the time of COVID-19: safety first. J Minim Invasive Gynecol. 2020;27:792-793.

10. COVID-19: protecting health-care workers. Lancet. 2020; 395:922.
11. Salazar CA, Isaacson KB. Office operative hysteroscopy: an update. J Minim Invasive Gynecol. 2018;25:199-208.

12. Cicinelli E. Hysteroscopy without anesthesia: review of recent literature. J Minim Invasive Gynecol. 2010;17:703-708.

13. Wax RS, Christian MD. Practical recommendations for critical care and anesthesiology teams caring for novel coronavirus (2019-nCoV) patients. Can J Anaesth. 2020;67:568-576.

14. Aslan MM, Yuvaci HU, Köse O, et al. SARS-CoV-2 is not present in the vaginal fluid of pregnant women with COVID-19. J Matern Fetal Neonatal Med. 2020:1-3. doi: 10.1080/14767058.2020.1793318.

15. Chen Y, Chen L, Deng Q, et al. The presence of SARSCoV-2 RNA in the feces of COVID-19 patients. J Med Virol. 2020;92:833-840

16. Prisant N, Bujan L, Benichou H, et al. Zika virus in the female genital tract. Lancet Infect Dis. 2016;16:1000-1001.

17. Rodriguez LL, De Roo A, Guimard Y, et al. Persistence and genetic stability of Ebola virus during the outbreak in Kikwit, Democratic Republic of the Congo, 1995. J Infect Dis. 1999;179 Suppl 1:S170-S176.

18. Qiu L, Liu X, Xiao M, et al. SARS-CoV-2 is not detectable in the vaginal fluid of women with severe COVID-19 infection. Clin Infect Dis. 2020;71:813-817.

19. Brat GA, Hersey S, Chhabra K, et al. Protecting surgical teams during the COVID-19 outbreak: a narrative review and clinical considerations. Ann Surg. April 17, 2020. doi: 10.1097/SLA.0000000000003926.

20. Kwak HD, Kim SH, Seo YS, et al. Detecting hepatitis B virus in surgical smoke emitted during laparoscopic surgery. Осcup Environ Med. 2016;73:857-863.

21. Zheng MH, Boni L, Fingerhut A. Minimally invasive surgery and the novel coronavirus outbreak: lessons learned in China and Italy. Ann Surg. 2020;272:e5-e6.

22. Catena U. Surgical smoke in hysteroscopic surgery: does it really matter in COVID-19 times? Facts Views Vis Obgyn. 2020;12:67-68

23. Carugno J, Di Spiezio Sardo A, Alonso L, et al. COVID-19 pandemic. Impact on hysteroscopic procedures: a consensus statement from the Global Congress of Hysteroscopy Scientific Committee. J Minim Invasive Gynecol. 2020;27:988-992. 